Journal of Research in Technical Careers

December 2019, Vol. 3, No. 2.

(C) Author(s)

\title{
Poverty Simulation Participation: Transformative Learning Outcomes Among Family and Consumer Sciences Students
}

\author{
Sally E. Arnett-Hartwick, Tamra S. Davis \\ Illinois State University
}

\begin{abstract}
The purpose of this study was to investigate to what extent participating in a poverty simulation effectively increases a student's understanding of life in poverty among human development and family sciences (HDFS) and teacher education students in family and consumer sciences (FCS). Using a mixed-method design, a convenience sample of junior and senior undergraduate students $(\mathrm{N}=57)$ in FCS from a midwestern state university participated in a modified version of a poverty simulation. Using a pre-post questionnaire, the quantitative results indicated overall scores moved in a favorable direction in attitude improvement toward the poor and the qualitative responses provided support for the poverty simulation as an effective instructional tool. The results included encouragement of more positive attitudes among the HDFS and teacher education students, providing future child care specialists, social service agents, and educators with an empathic and interaction basis for working with clients and students who are experiencing poverty.
\end{abstract}

Keywords: poverty simulation in family and consumer sciences, family and consumer sciences simulations teaching method

\section{Introduction}

Family and consumer sciences (FCS) students in human development and family science (HDFS) and teacher education areas will work with clients and students who live in poverty; however, these students are mostly from middle- and upper-class homes and have limited experience with poverty (Vandsburger, Duncan-Daston, Akerson, \& Dillon, 2010). In particular, these students will pursue positions as child care specialists, social service agents, and secondary teachers. To develop professional competency, FCS students must engage in learning opportunities that help them understand the multifaceted issues that affect the poor. One such instructional method that has potential to improve students' knowledge of poverty is the use of a poverty simulation (Clarke, Sedlacek, \& Watson, 2016).

Simulations are an experiential instructional tool that have been identified as being effective at changing knowledge, attitudes, and influencing future practice. Other 
disciplines, such as the health sciences, agriculture science, and social work, have used a poverty simulation that positively altered students' attitudes toward poverty (Crabb, 2018; Donahoe \& Gaddis, 2016; Navarro, 2009; Strasser, Smith, Pendrick Denney, Jackson, \& Buckmaster, 2013); however, do the same results apply to HDFS and teacher education students in FCS? Additionally, do HDFS and teacher education students believe the use of poverty simulation is an effective instructional tool to learn about poverty? Therefore, the purpose of this study was to investigate to what extent participating in a poverty simulation effectively increases a student's understanding of life in poverty among HDFS and teacher education students in FCS. The results can determine if transformational learning occurs among FCS students and demonstrate the instructional effectiveness of a poverty simulation to teach about poverty.

\section{Literature Review}

A significant number of families and children in the United States are experiencing economic distress defined as three times the inflation-adjusted cost of minimum food requirements (Center for Poverty Research, 2018). In 2017, 12.3\% of the U.S. population, equating to nearly 40 million Americans were living in poverty, and of those, 12.8 million were children according to the U.S. Census Bureau (2018). In the midwestern state in which this study took place, $13 \%$ of the population lived in poverty according to the official measure (Talk Poverty, 2018). The poverty threshold for a family of four in 2018 was set at \$25,100 (U.S. Department of Health and Human Services, 2018). Employment, food insecurity, living expenses, assets, savings, health care, education attainment, and housing are all factors that contribute to being classified as poverty-stricken. Because there is a large portion of families living in poverty, it is important that students understand the realities of poverty so that they may better help those in need.

Americans seem to have become desensitized to and have preconceptions about people who live in poverty (Kihm \& Knapp, 2015). For example, according to Gorski (2012), it is commonly believed that poor people are lazy, addicts, uninterested in education, and atfault for being poor. Given that most university students are from the middle- and uppersocio-economic classes and have little-to-no knowledge of the welfare system, these students develop unrealistic ideas and expectations about the poor (Hattery, 2003). This lack of experience and understanding is likely to reduce students' potential for competent professional intervention with the client/student population.

One such instructional method that has potential to improve students' knowledge of poverty is the use of a poverty simulation (Clarke et al., 2016). Evidence can be seen from multiple studies in disciplines, primarily related to health care or social services. Specifically, Hellman, Cass, Cathey, Smith, and Hurley (2018) concluded nursing students who participated in a poverty simulation experience gained an increased understanding of the vulnerability and complexities of living in poverty. Additionally, pharmacy students reported altered attitudes concerning poverty (Clarke et al., 2016) and social work students' knowledge about the difficulties of living in poverty improved (Zosky \& Thompson, 2012). Finally, Todd, de Guzman, and Zhang (2011) suggested multiple benefits of using a poverty simulation with general education students, including changes in attitudes and 
beliefs about how serious the experience of poverty can be, an increase in understanding that poverty is complex and multi-faced in cause, and a decrease in biases and stereotypes about people living in poverty. Among general FCS students, Kilm and Knapp (2015) facilitated a poverty simulation and found an overall favorable change in perception as a result of participation. Students reported having an increased awareness of the prevalence of poverty, as well as greater understanding of how various social service and government agencies function and the effects of poverty on family functioning. Poverty simulations have shown promise as a learning tool among undergraduate students in a variety of disciplines. In the current study, the researchers explore whether poverty simulations are effective with FCS HDFS and teacher education students in transforming attitudes toward poverty.

Conceptual Framework. In FCS coursework at the midwestern university studied here, the current practice is to teach the effects of limited resources among individuals and families through the use of passive methods such as lecture and providing articles related to poverty. Recognizing the need for students to develop an understanding of life in poverty to be well-prepared to work with low-income citizens, the use of an experiential learning activity such as a poverty simulation has been recommended to challenge student's perceptions and to adequately address the effect of poverty on poor people (Zosky \& Thompson, 2012). Experiential learning in its simplest form refers to learn by doing. Experiential education first immerses learners in an experience and then encourages reflection about the experience to develop new skills, new attitudes, or new ways of thinking (Association of Experiential Education, n.d.). MackIntosh (2014) believed experiential learning contributes to the transformative learning experience and supports shifts in point of view of the learner. Learning that is transformative occurs when situations cause one to question currently held frames of reference and, as a result, alter them to reflect their acquisition of knowledge because of an experience (Mezirow, 1994). Fanning and Gaba (2007) suggested adult learners need to participate in an experiential learning environment to learn effectively and transfer that learning to their own contexts.

Simulations are an experiential instructional tool that have been identified as being effective at changing knowledge, attitudes, and influencing future practice. Billings and Hallstead (2005) described simulations as a near representation of an actual life event through role-playing that actively involve learners in applying the content of the lesson. Simulations enable students to be active in their own learning which encourages a more personal connection with the academic content of other pedagogy courses. Krumer-Nevo, Weiss-Gal, and Monnickendam (2009) recommended the use of a poverty simulation to expose students to contextual factors and increase support for structural attributions for poverty. Further supporting the use of poverty simulations, Vandsburger et al. (2010) found that participation created a paradigm shift in relating to the poor.

The available research-primarily from the health sciences field--indicates that poverty simulations are a valuable tool for altering attitudes about poverty and raising empathy for those living in poverty. This study adds to the literature, because the impact of the simulation used in FCS is limited. Specifically, the use of the simulation among HDFS and teacher education students has not been discussed in current literature. Furthermore, from 
Journal of Research in Technical Careers

a qualitative focus, to specifically ask FCS students what they learned from the experience and if the poverty simulation was an effective instructional tool adds a unique contribution to the literature. Therefore, to strengthen the curriculum and increase the knowledge base, opportunities to develop competency with poverty-stricken clients or students must be provided in the classroom. By incorporating the simulation in career and technical education (CTE) disciplines, the students' career readiness and empathy will be strengthened. Understanding the complexities of living in poverty provides a bridge to allow future social service agencies, child care workers, and teachers to work more effectively with clients and students, especially when they lack the personal experience.

\section{Methods}

Purpose and Participants. The purpose of this research was to investigate to what extent participating in a poverty simulation effectively increases a student's understanding of life in poverty among human development and family sciences (HDFS) and teacher education students in FCS. Both quantitative and qualitative research designs were used to explore this topic. Specifically, the research objectives were:

1. Determine the impact of participating in a poverty simulation on attitudes toward poverty among HDFS and teacher education students in FCS (quantitative approach).

2. Identify what HDFS and teacher education students in FCS learned about poverty from participating in a poverty simulation (qualitative approach).

3. Determine if HDFS and teacher education students in FCS believe a poverty simulation is an effective teaching tool (qualitative approach).

Using a mixed-method design, a convenience sample of 57 junior and senior undergraduate HDFS and teacher education students in FCS from a midwestern state university participated in a poverty simulation. These students were enrolled in Resource Management for Individuals and Families, a three-credit-hour required course in fall 2018. Participants were all female (100\%), and class ethnicity included White $(n=44,77 \%)$, African American $(n=7,12.2 \%)$, and Hispanic $(n=6,10.5 \%)$. The simulation took place as a required class activity, but completion of pre- and post-questionnaires was voluntary.

Procedure. Researchers used a kit developed by the Missouri Association for Community Action (CAPS) as the tool to deliver the poverty simulation. This instructional kit was designed to help participants begin to understand what it might be like to be a part of a typical low-income family. According to the CAPS (2010) introductory statement, "the simulation will place you in the shoes of a person or family living in poverty" (p. 4).

The simulation mimicked a month of living with limited resources. Participants assumed a role in one of 26 family units varying in size from a single elderly person to a five-person multi-generational family. Each "family" was given a profile that described each family member's role, income, debt, and budget. In their assigned roles, each participant had to utilize decision-making skills to maintain their home and family life. Students outside of the course volunteered to portray community resources such as the 
grocery store, pawn shop, utility company, bank, child care center, homeless shelter, social service office, employer, school. Participants interacted with community resources to meet their family responsibilities during a specific time period in the simulation.

A modified version of the poverty simulation was used as result of the time constraints of a class period. The simulation occurred once a week during the 75-minute class period for four weeks. The simulation was divided into two 18-minute periods with each period representing one week. At the start of the session, students were assigned to a family. Following a seven-minute period to learn about their family, the facilitator blew the whistle to start week one [18 minutes], which was followed by a three-minute weekend, and repeated the procedure for week two. Immediately following the simulation, the students engaged in guided discussion with the entire group. Each week students were assigned to a new 'family,' thus role-playing four different family members.

Data Collection. The Attitude Toward Poverty (ATP) scale, originally developed by Atherton et al. (1993) to measure potential changes in attitudes toward poverty and people living in poverty, was adapted for this evaluation. Yun and Weaver (2010) validated the ATP through correlational analyses and independent $t$ tests and established its reliability and determined convergent validity. The subscales of the ATP used in this study included 12 items consisting of three factors - personal deficiency, stigma, and structural perspective. Participants indicated their level of agreement with each statement (how much it reflected their own viewpoint) using four options on a Likert scale (strongly reflects what I believe, somewhat reflects what I believe, I do not know, does not reflect what I believe). The questionnaire was placed on Qualtrics, the approved survey tool for the university.

Prior to the first simulation session, the students were briefed on the poverty simulation and the research component. Students were sent an email that included the link to the prequestionnaire. For the next four weeks, participants engaged in the poverty simulation. Following the last simulation, students were sent an email with the link to complete the same questionnaire along with two open-ended questions.

The pre- and post-questionnaire data were analyzed using SPSS. Descriptive statistics were calculated and summarized. Paired sample t-tests were used to evaluate changes in attitudes for each questionnaire item and for each factor using a Cronbach alpha value of 0.05. According to Atherton et al. (1993), the higher the overall score for the personal deficiency and stigma factors, the more favorable the attitude toward those living in poverty. In the structural factor, items were reverse scored; therefore, a lower scale score indicated movement in a positive direction. Responses to the two open-ended questions were independently coded by the two researchers and two reviewers to establish themes through an open coding process. Results were compared and discussed to arrive at consensus and establish credibility and trustworthiness of the data.

\section{Results}

Overall scores moved in the positive direction, demonstrating a more favorable attitude toward the poor populations in the factors of personal deficiency, stigma, and structural perspective. Zar (2009) noted changes in pre- and post-test mean scores can indicate 
Table 1. Scores for ATP items and factors

\begin{tabular}{|c|c|c|c|c|}
\hline Statement & $\begin{array}{l}\text { Pretest } \\
\text { Mean } \\
(\mathrm{N}=57)\end{array}$ & $\begin{array}{l}\text { Posttest } \\
\text { Mean } \\
(\mathrm{N}=57)\end{array}$ & $t$ value & $p$ value \\
\hline \multicolumn{5}{|l|}{ Factor: Personal Deficiency } \\
\hline Poor people are lazy. & 2.66 & 2.85 & -1.771 & 0.083 \\
\hline Poor people watch too much TV. & 3.00 & 2.96 & 0.530 & 0.598 \\
\hline $\begin{array}{l}\text { Poor people spend too much money on junk food } \\
\text { and fast food. }\end{array}$ & 2.55 & 2.85 & -2.455 & $0.018 *$ \\
\hline Poor people have low self-esteem. & 2.12 & 2.11 & 0.121 & 0.904 \\
\hline Overall Score & 10.33 & 10.77 & -1.266 & 0.295 \\
\hline \multicolumn{5}{|l|}{ Factor: Stigma } \\
\hline $\begin{array}{l}\text { The community provides effective and efficient } \\
\text { services to help families with low income live. }\end{array}$ & 2.34 & 2.40 & -0.408 & 0.685 \\
\hline $\begin{array}{l}\text { People with low income do not have to work as hard } \\
\text { because of all the services available to them. }\end{array}$ & 2.79 & 2.89 & -1.000 & 0.323 \\
\hline $\begin{array}{l}\text { People with low income get a lot of breaks with } \\
\text { respect to things like rent, utilities, and other } \\
\text { expenses. }\end{array}$ & 2.84 & 2.89 & 0.596 & 0.554 \\
\hline $\begin{array}{l}\text { People get enough money to survive from welfare, } \\
\text { food stamps, and other social programs. }\end{array}$ & 2.76 & 2.89 & -1.182 & 0.244 \\
\hline Overall score & 10.73 & 11.07 & -1.336 & 0.274 \\
\hline \multicolumn{5}{|l|}{ Factor: Structural Perspective } \\
\hline $\begin{array}{l}\text { People are generally responsible for whether they } \\
\text { are poor. }\end{array}$ & 2.51 & 2.64 & -0.948 & 0.348 \\
\hline $\begin{array}{l}\text { People with low income could improve } \\
\text { their situation if they wanted to. }\end{array}$ & 2.47 & 2.51 & -0.321 & 0.749 \\
\hline Society has the responsibility to help poor people. & 2.29 & 2.08 & 1.374 & 0.176 \\
\hline $\begin{array}{l}\text { There are emotional costs associated with being } \\
\text { poor. }\end{array}$ & 1.56 & 1.33 & 1.258 & 0.215 \\
\hline Overall score & 8.83 & 8.56 & 0.747 & 0.509 \\
\hline
\end{tabular}

Note. ${ }^{*} \mathrm{p}<.05 \mid$ Scale: Strongly reflects what I believe, Somewhat reflects what I believe, I do not know, Does not reflect what I believe

whether participants' knowledge increased or decreased for the population studied. Improvement in attitudes were noted in eight of the 12 questionnaire items (Table 1). Although the overall score for the personal deficiency domain improved, two of the four items narrowly did not improve (Poor people watch too much TV and Poor people have low self-esteem). Only one item on the questionnaire, Poor people spend too much money on junk food and fast food, proved to be statistically significant $(p=<0.05)$. Within the stigma factor, attitude improvement was found in each of the four items. The four items in the structural perspective factor indicated change, with improvement among two items (Society has the responsibility to help poor people and There are emotional costs associated with being poor) while the other two items showed a decline in attitude (People 
are generally responsible for whether they are poor and People with low income could improve their situation if they wanted to).

Question one on the post-questionnaire asked, “After completion of this simulation, what did you learn about poverty?" Three themes emerged from the responses: difficulty of living in poverty, implications for the family, and access to resources. In the first theme, difficulty of living in poverty, the most common responses used adjectives such as "difficult," "hard," "stressful," "frustrated," and "not easy," to describe what they learned from the simulation. Comments included:

- “...is so much harder than its stigma”;

- "Poor people struggle every day with something”;

- 'I'm guilty of judging the lives of homeless people and poor people in the past, but after this, I know that it is so much more complicated than they can get a job at any time";

- "I learned people in poverty don't always have a say in getting out of poverty because if they cannot find a job, they can't control when they will pay their bills or be able to afford food and housing"; and

- "I have gained respect for people in poverty, it’s not easy and super stressful. "I have such a greater understanding of the struggles of poverty - I am thankful to have had this experience.”

A second theme was poverty has many implications for the family. Responses included:

- "I learned that there are several things that families struggle with that I did not even consider - transportation and childcare";

- "tough choices need to be made that can compromise the well-being of the family";

- "trying their hardest to provide for everyone in their family and have to make sacrifices";

- "poverty has a snowball effect”; and

- “I didn’t know the pressure one must feel on a daily basis when other people such as a spouse or children are counting you."

Access to resources emerged as the third theme to what students learned from participating in the simulation. Comments included:

- "I learned about resources, such as welfare benefits, that were available to me to make ends meet and function";

- " "it's hard to find the resources, where to go, and finding the time and people to help you";

- "the value of being able to ask for help and know where you can find resources"; and

- "doing this simulation has pushed me to think of ideas for my future business that I can help people who cannot afford it."

Question two on the post-questionnaire asked, "Is participating in a poverty simulation an effective teaching tool? The most common response was, "the simulation was an eye- 
opening experience." Three themes were identified to the effectiveness of using a simulation as a teaching tool, which included personal placement, learning modality, and career preparation.

The first theme was personal placement. Responses that reinforced this theme included:

- "makes you look at your values and manipulates what you think";

- "put myself in someone else's shoes and understand their daily struggles that others take for granted";

- "causes people who have never lived in poverty to gain empathy";

- "gave me a deeper understanding of things I never had to experience";

- "I do not come from poverty and it helped me understand poor people are not lazy and how difficult it really is";

- "I gained respect for those living in poverty and so appreciative of my upbringing"; and

- "makes you want to find ways to help in the community however small - such as paying it forward in a McDonald's drive through."

Learning modality was the second theme. Comments included:

- "you can read all about poverty and have an idea of what it would be like in your head but when you actually simulate it, you get to feel all of these different emotions that you didn't realize you would feel. I was stressed during the simulation and it wasn't even for real";

- "extremely beneficial tool - it is a nice break from the traditional classroom lecture, which added an extra level of interest by getting to play a different family member each week";

- "interactive tool and gives students as close to real life experiences as possible than just taking notes and sitting at a desk"; and

- "hands-on experience of being in poverty was more beneficial that just sitting in a lecture hearing stories and statistics about poverty."

The third theme was career preparation. Statement items that supported this theme included:

- "made me more aware of the challenges which prepare us as to what to expect with students or clients we are working";

- "gave me insight into how to better prepare myself as I will be working with clients who are in poverty and need assistance"; and

- "from this experience, I have more compassion and empathy for those who I will be working with that are living in poverty."

\section{Discussion}

The purpose of this study was to investigate to what extent participating in a poverty simulation effectively increases a student's understanding of life in poverty among HDFS and teacher education students in FCS. The quantitative data suggested improvements in 
attitude, while the qualitative data produced themes providing enriching context to inform future curriculum and instructional practice. The poverty simulation encourages more positive attitude among HDFS and teacher education students regarding their perception of poverty, expanding upon the work of others who found success with the simulations among extension educators, and undergraduate students in nursing, social work, pharmacy, and general education (Clarke et al., 2016; Franck, Barnes, \& Harrison, 2016; Hellman et al., 2018; Kihm \& Knapp, 2015; Zosky \& Thompson, 2012).

While not statistically significant, all individual statements in the questionnaire showed improvement in attitudes with the exception of four items. The statements Poor people watch too much TV, Poor people have low-self-esteem, People are generally responsible for whether they are poor, and People with low income could improve their situation if they wanted to showed a negative, though insignificant, change from pre- to post-simulation. Given that self-esteem is a relatable emotion state, the simulation may have raised participants' awareness of the impact of poverty on one's self-esteem. Repeatedly making attempts to improve their situation during the simulation only to be met with setbacks and obstacles may have led the participants to realize that one's self esteem may be negatively influenced by living in poverty. While the statistical significance of the quantitative data was limited, the qualitative data provide further evidence and arguably a better understanding of the transformative learning process undertaken by the participants in this study. Statements provided by the participants in response to the two open-ended questions illustrate the transformation that occurred during the simulation. The experience of living in poverty, something they had not experienced before, opened their eyes to the daily lived experiences of those in poverty, providing a deeper understanding of the challenges encountered by the poor. In addition, the participants also noted that the simulation prompted them to engage in self-reflection about their own living circumstances, particularly in comparison to those living in poverty. Their responses as well as the reported quantitative data supported MackIntosh's (2014) and Mezirow's (1994) descriptions of a transformative learning process during which a learner experienced a shift in point of view.

The learning accounts described by the participants revealed the positive impact the poverty simulation had on them. Basic frustration was conveyed by participants with descriptors such as "difficult," "stressful," "hard,” and "struggle”. One participant reported, "I was stressed and it wasn't even for real." The participants had the opportunity to experience the complex, interrelated issues of poverty with food supply, child care, transportation, character of people, family dynamics, and time. Participants commented "that poverty has a snowball effect," and “... families struggle with things that I did not even consider - transportation and childcare." These comments reiterate the findings of Hellman et al. (2018) and Todd et al. (2011) that the poverty simulation creates an understanding of the interwoven complexities' poverty presents. Like Kilm and Knapp (2015), participants in this study recognized that access to resources is crucial to overcome even the daily obstacles of living in poverty. Responses by participants included "...hard to find resources" and "...finding the time," thus acknowledging the need to have more resources available and inform those in need about what resources are available and where to go. 
The poverty simulation, grounded in experiential learning, proved favorable as a learning modality among the participants in this study. One participant noted that it was an "extremely beneficial tool - a nice break from traditional lecture." Others added that it was an "interactive tool," "hands-on experience," and "got to feel the emotions." An added benefit as a result of the modified version used; one student acknowledged that the simulation "added an extra level of interest by getting to play a different family member each week." Like Billings and Hallstead (2005), participants in this study were actively involved learners in applying the content; as one participant in this study remarked, the simulation "... was more beneficial than just sitting in a lecture hearing stories and statistics about poverty.”

Because most undergraduate students come from a privileged background, this experience can help increase competent professional intervention among HDFS and teacher education students who will work with low-income clientele or student populations. Through participation in the simulation activities, the participants were able to project how they would use the experiences learned into their future careers. Statement items such as "I have more compassion and empathy for those I will be working with," and that they are "more aware of the challenges which better prepare us what to expect with students or clients we are working with" confirm an increase in professional competency.

Interestingly, a few comments indicated a vow to make a difference. One participant noted that this experience "...makes you want to find ways to help in the community however small - such as paying it forward in McDonald's drive” while another participant commented, "doing this simulation has pushed me to think of ideas for my future business that I can help people who cannot afford it." These two comments indicate the personal takeaway in wanting to better their community.

Given that most university students are from the middle and upper class and have littleto-no knowledge about poverty (Vandsburger et al., 2010), the poverty simulation proved to be as much of an effective teaching tool for participants in this study as it was for Patterson and Hulton (2011). Several participants acknowledged their own lack of personal experience with poverty and expressed the value of the simulation in helping them gain a deeper understanding of poverty challenges, as well as enhanced empathy for those living in poverty and greater appreciation for their own upbringing. Thus, the simulation increased awareness and positively encouraged the participants in multiple ways - their attitudes, viewpoints, thoughts, feelings and future directions as educators. As one participant stated, "it put myself in someone else's shoes to understand their daily struggles that I and many others take for granted," confirming the CAPS (2010) introductory statement indicating that the simulation will place participants in the shoes of a person or family living in poverty.

\section{Conclusion}

The results of this study indicate that the use of a poverty simulation was beneficial in increasing understanding of life in poverty among HDFS and teacher education students in FCS. In spite of limited statistically significant results, the quantitative data suggested improvements in attitude, and the qualitative results produced themes for informing future 
curriculum and instructional practice. When students are exposed to experiential learning modalities, such as the poverty simulation, they start to understand the complexity of living in poverty. This understanding provides a bridge to enable HDFS and teacher education students in FCS to work more effectively with clients or students, especially when they lack the personal experience. Additionally, this study expands on the existing poverty simulation research and, moreover, adds an FCS context to the literature base.

Limitations of this study included the use of self-reporting of the data among participants. Additionally, one group was studied, and the sample was homogenous, thus limiting transferability. Recommended future research includes a longitudinal study to establish a pattern of the poverty simulation as an effective instructional tool and to followup with the participants in this study to determine what participants did as a result of this experience. Additionally, as FCS is a part of career and technical education (CTE), programs in CTE can use this study as a resource to model the poverty simulation format and research the effects of the simulation with their respective students.

Considering the chosen major of these students and the fact that $13 \%$ of residents in this midwestern state live in poverty, increases the likelihood of graduates of this institution will work with people living in poverty in some facet. Beyond reading about poverty, active opportunities to develop this professional competency (career readiness and empathy development) should be provided in the curriculum. Overall, the results and findings of this study confirmed the positive impact of using a poverty simulation as an instructional tool in this FCS class to engage students in the learning process about poverty.

\section{References}

Association of Experiential Education. (n.d.). Retrieved from https://www.aee.org/

Atherton, C. R., Gemmel, R. J., Haagenstad, S., Holt, D. J., Jensen, L. A., O’Hara, D. F., \& Rehner, T. A. (1993). Measuring attitudes toward poverty: A new scale. Journal of Social Work, 29(4), 28-30. https://doi.org/10.1093/swra/29.4.28

Billings, D. M., \& Halstead, J. A. (2005). Teaching in nursing: A guide for faculty (2nd ed.). St. Louis, MO: Elsevier.

Center for Poverty Research. (2018). Retrieved from https://poverty.ucdavis.edu/faq/whatcurrent-poverty-rate-united-states

Clarke, C., Sedlacek, R. K., \& Watson, S. B. (2016). Impact of a simulation exercised on pharmacy student attitude toward poverty. American Journal of Pharmaceutical Education, 80(2), 1-7. https://doi.org/10.5688/ajpe80221

Crabb, J. L. (2018). The impact of a poverty simulation on practical nursing students' attitudes towards poverty (Doctoral Dissertation). Retrieved from DNP Scholarly Projects. 14. https://commons.nmu.edu/dnp/14

Donahoe, J., \& Gaddis, A. (2016). Students' responses to experiential learning using the poverty simulation. Presented at the meeting of North American Association of Christians in Social Work, Cincinnati, OH.

Fanning, R., \& Gaba, D. (2007). The role of debriefing in simulation-based learning. Society for Simulation in Healthcare, 2(2), 115-25. https://doi.org/10.1097/SIH.0b013e3180315539

Franck, K. L., Barnes, S., \& Harrison, J. (2016). Poverty simulations: Building relationships among extension, schools, and the community. Journal of Extension, 54(1). 
Hattery, A. J. (2003). Sleeping in a box, thinking outside the box: Student reflections on innovative pedagogical tools for teaching about and promoting a greater understanding of social class inequality among undergraduates. Teaching Sociology, 31, 412-427. https://doi.org/10.2307/3211366

Hellman, A., Cass, C., Cathey, H., Smith, S., \& Hurley, S. (2018) Understanding poverty: Teaching social justice in undergraduate nursing education. Journal of Forensic Nursing, 14(1), 11-17. https://doi.org/10.1097/JFN.0000000000000182

Gorski, P. (2012). Perceiving the problem of poverty and schooling: Deconstructing the class stereotypes that mis-shape education practice and policy. Equity and Excellence in Education, 45, 302-319. https://doi.org/10.1080/10665684.2102.666934

Kihm, H., \& Knapp, S. (2015). The poverty simulator: Experiential learning for family and consumer sciences students. Journal of Family and Consumer Sciences Education, 32(1), 2428.

Krumer-Nevo, M., Weiss-Gal, I., \& Monnickendam, M. (2009). Poverty- aware social work practice: A conceptual framework for social work education. Journal of Social Work Education, 45, 225-243. https://doi.org/10.5175/JSWE.2009.200600144

MackIntosh, L. (2014). Just doing it: The role of experiential learning and integrated curricula in architectural education. The International Journal of Pedagogy and Curriculum, 20(3), 6778. Retrieved from https://espace.curtin.edu.au/handle/20.500.11937/13590

Mezirow, J. (1994). Understanding transformation learning. Adult Education Quarterly, 44(4), 222-232. https://doi.org/10.1177/074171369404400403

Missouri Association for Community Action. (2010). Community action poverty simulation (CAPS). Jefferson City, MO: MACA.

Navarro, M. (2009). Transforming the curriculum: Using hunger issues to enhance teaching and learning. North American Colleges and Teachers of Agriculture, 53(2), 15-20.

Patterson, N., \& Hulton, L. J. (2012). Enhancing nursing students' understanding of poverty through simulation. Public Health Nursing, 29(2), 143-151. https://doi.org/10.1111/j.15251446.2011.00999.x

Strasser, S., Smith, M. O., Pendrick Denney, D., Jackson, M. C., \& Buckmaster, P. (2013). A poverty simulation to inform public health practice. American Journal of Health Education, 44, 1-6. https://doi.org/10.1080/19325037.2013.811366

Talk Poverty. (2018). Retrieved from https://spotlightonpoverty.org/states/illinois/

Todd, M. E., de Guzman, M. R., \& Zhang, X. (2011). Using poverty simulation for college students: A mixed-methods evaluation. Journal of Youth Development, 6(2). Retrieved from http://digitalcommons.unl.edu/famconfacpub/102

Vandsburger, E., Duncan-Daston, R., Akerson, E., \& Dillon, T. (2010). The effects of poverty simulation, an experiential learning modality, on students' understanding of life in poverty. Journal of Teaching in Social Work, 30(3), 300-316. https://doi.org/10.1080/08841233.2010.497129

Yun, S. H., \& Weaver, R. D. (2010). Development and validation of a short form of the attitude toward poverty scale. Advances in Social Work, 11(2), 174-187. https://doi.org/10.18060/437

Zar, J. H. (2009). Biostatistical analysis (5th ed.). Prentice-Hall, N.J.

Zosky, D., \& Thompson, J. (2012). Poverty simulation: An experiential learning tool emphasizing economic justice content. Journal of Baccalaureate Social Work, 17(1), 69-84. 